\title{
European Policies in TEFL Teacher Education
}

\author{
José Manuel Vez*
}

\author{
Director of the OAL (Observatorio Atrium Linguarum), Institute for Education Sciences. University of Santiago de \\ Compostela, Spain
}

\begin{abstract}
This research article attempts to create a link between the problems that arise when we try to introduce a European dimension in foreign language teaching, particularly with respect to the role teacher education institutions and programmes should play. A shift in emphasis in foreign language teaching from form-oriented to more communicationoriented work and culture-oriented work should not only make TEFL (Teaching of English as a Foreign Language) approaches in Europe more efficient and effective, but also, at the same time, offer the chance of introducing a European dimension into the very heart of the teaching of English as a foreign language. This means that EFL (English as a Foreign Language) teachers, more responsibly and knowledgeably than was the case in the past, will give shape to a kind of intercultural foreign language education in which the unique ways of communicating in the various European communities are highlighted. If done in the right way, this could stimulate in our youth an awareness of their own culture and respect for the culture of other speech communities and nations with which we are forming a political and monetary union. Below, an attempt will be made to elucidate this idea.
\end{abstract}

Keywords: European dimension, foreign language teacher education, multilingual and intercultural communication, EU language policies.

\section{INTRODUCTION}

Foreign language education, in line with current innovation trends all over Europe, may be viewed within the framework of an interparadigmatic change which is characterised by the generally accepted feeling that language is the most significant social activity human beings are able to perform.

From a time in which there was neither a popular nor an educational consensus about the part foreign languages should play in students' life at school, we have moved to a position in which foreign language education plays a central role in our (primary and secondary) curriculum development and in teacher education, both initial and in-service.

Since the previous report for the SIGMA project (Buchberger and Beernaert, 1996) was written and, later on, the updated version of the final report was published (TNTEE Publications, 1999), some important changes occurred in teacher education policies in different countries in Europe concerning (i) initial teacher education, (ii) inservice teacher education, and (iii) further teacher education steps in favour of language educational tasks conceiving a multilingual and intercultural European dimension. Still, education of most nationals and almost all immigrant minorities participates in committing linguistic imperialism, via EFL, instead of supporting the languages that could enrich Europe via inter-comprehension in various European languages. There are many different explanations about this situation, even from the most radical side of the problem. But facts are the way they are and, year after year, an English-only Europe (Phillipson, 2002) is growing up and up. Anyhow this is not the point here. I will refer to the

*Address correspondence to this author at the Instituto de Ciencias de la Educación, Ave. de las Ciencias, Chalet 4, Campus Sur, University of Santiago de Compostela, Spain; E-mail: josemanuelvez@usc.es necessity of maintaining a liberal diversity of languages and cultures, including English, as part of the cultural support of an authentic European dimension in foreign language teaching.

Of course achieving high levels of competence in English is something that enhances one's chances on the labour market. The question is not whether or not children should learn English at European schools -of course they should. The question is how they can best do it having into account the fact that in most situations in the world using English as the unique medium of foreign language education for nonEnglish speaking children is not a solution. Moreover, it is a big problem.

The globalisation that accompanies the neo-liberal ideology of the free markets is closely linked to the expanding international use of English. As Leonard Orban, EU Commissioner for Multilingualism, has recently put it (Retrieved January 12, 2008 from http://ec.europa.eu/ commission_barroso/orban/index_en.htm):

From the moment I took up this portfolio, the interface between business and languages has been one of my priorities. Multilingualism is a plusfactor for European integration, competitiveness, growth and better jobs. Our challenge is to get the message across to business and to education, and to arm companies and individuals with the language tools and strategies for success. Multilingualism touches citizens directly. Just an example: over 2400 responses to our on-line languages consultation this autumn, when, often, the Commission is receiving a couple of hundred. This is not surprising. Citizens view this policy as a means to articulate a democratic right: to understand EU policy and to be understood by the institutions. Seen from this perspective, the cost of multilingualism -roughly the price of a coffee per citizen per year-is negligible and, in any event, is the cost of democracy. 
As we all know, since World War II English has become the dominant international language, and that process is now accelerating with the USA as the one remaining superpower. Other international linguas francas (such as French in western industrialised societies or Russian in the former eastern block) are in decline. Englishization is socially divisive in that a knowledge of English is increasingly a condition for access to social positions and resources (including access to elite positions in the new neo-liberal economy), yet in many societies it is the wealthiest and best educated people who also have the best access to English. This is accentuated by the fact that most of the knowledge on which the knowledge-based economy operates is knowledge in English; and English is the main language of international institutions. Thus one aspect of research on language teaching and learning in the new neo-liberal europeanization -relating to the category of economic and political 'semiotic systems'- is on its relationship to 'Englishization': how that privileges particular countries and elites, new forms of multilingualism, the consequences in terms of the marginalisation of other languages, and in terms of 'linguistic human rights' (Phillipson and Skutnabb-Kangas, 1999).

In a Europe that strives for unity in more and more fields of human enterprise -cultural, economic, juridical and perhaps even political- communication between member states and, at the grass-roots level, between individuals across borders and cultures is of the most vital importance. In all the challenges offered to us by the growth towards real integration of the various nationalities into what Churchill already called "The United States of Europe", a reasonable spoken and/or written command of at least two, if not even three, languages spoken within its perimeter takes absolute priority. Without it the free movement of persons becomes a hollow phrase. A policy aimed at making one or two major languages the exclusive means of communication across state borders at the expense of many others will only seemingly simplify European integration. Refusing to meet the challenge of maintaining a liberal diversity of languages and cultures will not only culturally impoverish the Europe of the future, it will also cause resentment on the part of the minority language communities. Foreign language learning and teaching, also of minority languages, giving explicit attention to the socio-cultural aspects of the target language community, therefore, will remain a central task of education -in particular, teacher education- in European member states and deserves a lot of attention and investment of means.

The unification of Europe at grassroots level is facing problems which, perhaps, are even bigger than those at the top. The latter will eventually be overcome, if only because of economic necessity. However, work towards a solution of the problems at the basis of the European Community has hardly started yet. Only recently does the bottom-up process of establishing empathy with Europe and a sense of European citizenship in our youth through education seem to have become a serious issue in Brussels. Ignorance among the young of other ways of living and other forms of social interaction in the various national and speech communities of Europe is a marvellous breeding ground for ethnocentrism and mutual stereotyping. Such stereotypes may have a longlasting influence on a naïve and undeveloped mind if education does not provide an antidote. If we want a European sense of belonging to develop, and at the moment one has to look high and low to find a trace of one, teacher education will have to take on the responsibility for promulgating, even promoting "European-ness".

This paper attempts to create a link between these two problems. A shift in emphasis in foreign language teaching from form-oriented to more communication-oriented work and culture-oriented work should make TEFL approaches more efficient and effective, and also, at the same time, offer the chance of introducing a European dimension into foreign language teaching. This means that foreign language teachers, more responsibly and knowledgeably than was the case in the past, will give shape to a kind of intercultural foreign language education in which the unique ways of communicating in the various European communities are highlighted. If done in the right way, this could stimulate in our youth an awareness of their own culture and respect for the culture of other speech communities and nations with which we are forming a political and monetary union. Below, an attempt will be made to elucidate this idea. First looking at a few problems can best do this.

\section{INITIAL PROBLEM AREAS}

a) It is important to recognise here the fact that, since 2000, the European Union has increased attempts to improve language teaching and learning. The European Year of Languages in 2001 showed how language learning could be promoted at a European and national level. In 2002, the Barcelona meeting of the European Council proposed that European citizens should be taught at least two foreign languages, besides their mother-tongue, from an early age. The education of foreign language teachers is of increasing importance because of their key role in improving foreign language learning and awakening learners' interest in languages. In that way, we believe language teachers (of any language) play a major part in achieving the European Union's objective that all EU citizens should have linguistic competence in their own mother tongue and two other languages.

Following that, and considering particularly the fact that life-long learning initiatives would benefit from greater cooperation and harmonisation at a European level, an European Profile for Language Teacher Education (A frame of reference) has been recently launched as a Final Report to the European Commission, produced by M. Kelly, M. Grenfell, R. Allan, Ch. Kriza and W. McEvoy in September, 2004 (see Kelly et al., 2004).

This Report (there is also a short version of the Profile, edited by Michael Kelly and Michael Grenfell from the University of Southampton) proposes a European profile for language teacher education in the 21 st century. It deals with the initial and in-service education of foreign language teachers in primary, secondary and adult learning contexts and it offers a frame of reference for language education policy makers and language teacher educators in Europe. The findings draw on consultation with a wide range of European experts on language teacher education, and on the experience of eleven European teacher education institutions. The findings also suggest guidelines for quality assurance and enhancement. 
By outlining the key elements in European language teacher education, the Profile (supported by the European Commission) aims to serve as a checklist for existing teacher education programmes and a guideline for those still being developed. The Profile presents a toolkit of 40 items which could be included in a teacher education programme to equip language teachers with the necessary skills and knowledge, as well as other professional competencies, to enhance their professional development and to lead to greater transparency and portability of qualifications.

Of particular interest for the purpose of our paper is the explicit reference, in chapter 38 of the Profile, to the introduction of the concept of European citizenship: one type of citizenship in a chain linking regional, national, international and global citizenship. European citizenship should be promoted in many other areas besides (foreign) languages; this demands collaboration with colleagues from other disciplines and pan-European collaboration.

In spite of much lip-service paid to the importance of the development of oral proficiency in foreign language teaching, this aspect of linguistic skill has never had any real priority in the foreign language classes in a majority of European countries for a number of reasons, which will not be dealt with here. I have given explicit reasons about this problem with respect to the educational situation in Galicia somehow (Vez \& Martinez, 2002). Reading skills still form the nucleus of the national examination of linguistic skills. The testing of oral communicative skills (which are usually interpreted as meaning: speaking skills) is left to the schools themselves. Somehow the emphasis in language teaching policy will have to be shifted. This will not prove easy.

b) Even if the tradition in foreign language teaching could be influenced to such an extent that oral communicative skills would become the focus of teaching and learning, it would prove impossible to prepare the learners, in the time allowed (the European average time is about 4-6 years), for all the situations in which they may be called upon to function in the foreign language later. Therefore, we shall have to help and stimulate them to make as efficient and effective use as they can of what language command they have acquired in school. In other words we shall have to help them develop their strategic competence in order to compensate for shortcomings in their language proficiency and to stimulate their ability to negotiate meaning appropriately. Too little attention is paid to this aspect of language command at present in a vast majority of European countries.

c) One of the most frustrating consequences of an inadequate command of a foreign language is the fact that one cannot play the desired role in communicating with speakers of that language. In order to be able to do this one must dispose of a set of interactional routines. During exchanges of staff and pupils between schools, which are strongly stimulated at present, learners may find themselves staying in families abroad. Pupils will subsequently need to be able to function discursively on a different level from the one they naturally use in their peer-group. Classroom teaching, generally speaking, does not pay sufficient attention to the discourse routines they are then in need of (Faerch et al., 1984). If these routines are sufficiently automatised, they may not only enable the speaker to play the desired role in the interaction, they also give him or her time to activate his (socio) linguistic and intercultural competence (Byram et al, 2002). Moreover, as research suggests, they also play a stimulating role in the language acquisition process (Hatch, 1983).

d) The European spirit is hardly evident in large sections of the population of the European states. A lot of stereotyping of each other's cultures is at the basis of a lot of jokes that are bandied about, and the emotions engendered by international football championships could hardly be considered a sound basis for generating new feelings of European solidarity. Personal and socio-cultural filters prevent us from seeing the other culture in its true perspective. These filters consist of criteria that we have developed ourselves or which have been instilled in us by the socio-cultural group to which we belong. They find their origin in unpleasant personal experiences or in historical events that have determined the present political or economic situation. They cause us to find certain things normal or good, and others strange or even wrong. These attributive concepts are handed on to our own cultural surroundings as characteristic of the other culture. The problem is that the other culture is not given a fair deal as incompleteness in the information is accepted. Thus, the image we have, or get, of the other culture is warped. We then proceed to generalise on the basis of such partial and incomplete information to our heart's content. Feelings of solidarity with the other culture become then difficult if not impossible.

Foreign language teaching can contribute to counteracting such undesirable trends, which are so frustrating for European unification. Of central importance here is the development of a sensitivity in the learner for the otherness of the other culture through an emphasis on the different ways in which the other speech community generally reacts to life and does things with words (differences in discourse regulation and speech-act realisation). An important aspect of this sensitivisation is the development of the above-mentioned strategic competence (and a meta-communicative awareness of this competence) during the teaching-learning process. This competence helps the learner to learn to negotiate meaning and to help himself when his (socio) linguistic competence is inadequate or lets him/her down.

The meaning that is negotiated in international discourse is full of cultural pitfalls, and misunderstandings are lying in ambush. Certain sensitivity to possibilities and possible problems coupled with a linguistic capability to negotiate meaning is of great importance for successful intercultural communication. An insight into the way in which foreign language discourse is regulated guides the learner into the quintessence of the otherness of the other culture. Superficial stereotyping on the basis of practical knowledge may thus be discouraged. The learner may be induced to put his or her own culture in perspective instead of considering it the absolute norm by which everything else has to be judged. The problem is, of course, that in our school curricula hardly any attention is paid to aspects of communicative competence like this. Oral discourse, at best, comes at the bottom of the list of proficiency requirements, and consciousness -raising concerning discourse phenomena seems out of the question (Vez \& Martinez, 2002). 
e) At present, it is only geography and history teachers and, exceptionally, economics teachers who, in the course of their professional education, are brought into contact with Europe's unification process in some of its facets. In view of the importance of foreign language teaching for the success of this process, language teachers, too, will have to be given a thorough introduction to Europe (Beernaert, Van Dijk, Sander, 1993). They need this in order to co-operate with their geography and history colleagues in school projects. For the time being, however, such introductions do not yet feature very largely in foreign language teacher education curricula neither in Spain nor elsewhere in Europe.

\section{IMPLICATIONS FOR FOREIGN LANGUAGE TEACHER EDUCATION}

In the light of the above-mentioned problem areas we will have to devote explicit attention in initial and in-service foreign language teacher education, to discourse phenomena and speech-act realisation. Both of these reveal how people use their meaning potential in their particular culture-specific way. Also, as suggested above, concentrating on the formulaic nature of speech-acts and discourse regulation is an effective way of setting about foreign language teaching. In writing the foreign language teacher education curriculum it is just as indispensable to pay careful attention to the regulation of oral interaction as to the morpho-syntactic properties of the foreign language. If we wish to introduce the European context into language teaching this regulation, with its sociocultural and meta-cognitive basis, can no longer be ignored. Raising the learner's consciousness of the grammar of oral interaction must no longer be left to chance as has been done for so long in the past.

To be sure, the acquisition of pragmatic and discourse skills in the foreign language was, and still is, guaranteed here and there in teacher education by offering the student an extended stay in the target language country. The chances of being allowed such a stay, however, are slim for the individual student, even today in the age of extended programmes like ERASMUS and LINGUA. Such a stay, however, is of the greatest importance for the foreign language teacher to help him develop an insight into the regulation of foreign language discourse and give him an opportunity of becoming skilled in its manipulation. Policy makers in Brussels seem to have underscored such a statement with their LINGUA programme. However, the length of the LINGUA stay abroad appears a major obstacle for most teacher education institutions, as their professionoriented programmes cannot easily accommodate such a long absence of the student (Bruce, 1990). Shorter (too short?) stays of just one month are now being considered.

Therefore, a raising of the student's awareness of discourse and speech-act conventions and formulas is necessary. No less so for those students who are lucky enough to be allowed a lengthy stay abroad. For they may pick up an easy fluency in the foreign language during such a stay (invaluable in itself as this may be!), but it seems naive to expect them to go in for sufficient reflection on pragmatic and discourse differences between mother-tongue and foreign language. This is as unwarranted as expecting foreign language learners in a natural acquisition situation, and without a basic grounding in grammar, to develop a conscious knowledge of the foreign language's morphosyntactical regulation. The study of morphology and syntax is, and has been, since time immemorial considered a matter of course in foreign language teacher education curricula. By the same token a study of speech-act realisation and discourse regulation should be made a compulsory component of the TEFL student teachers' professional curriculum.

In the preceding section discourse regulation and speechact realisation were taken together. It may be useful to deal with speech-act realisation separately here. A foreign language teacher needs an insight into how things are done with words in the foreign (and contrastively his or her own) language. S/he needs an insight into the distinction between direct and indirect, conventional and unconventional speechacts if $\mathrm{s} / \mathrm{he}$ is to heighten his or her awareness of how language works in human interaction (Grenfell and Harris, 2007). This awareness forms the basis of his or her evergrowing realisation of how the other speech-community often looks at reality differently, and of how members of that community deal with one another differently, in other words of how that community has a different cultural perspective from his or her own. When using indirect and unconventional speech-acts, for example, we appeal to knowledge we share with our interlocutor. We take it for granted that s/he will understand our implications, and that $\mathrm{s} /$ he shares our discourse rules.

Teachers who have developed a respectful insight into the otherness of such conventions in the foreign language are satisfactorily equipped to immunise their students against the tendency to stereotype other speech communities or nations on this point. They can show how relative such conventions -including mother-tongue conventions- are and that what seems funny or strange or even weird, is nothing but another way of dealing with reality, intrinsically neither better nor worse than what is customary in the mother-tongue. Study of discourse conventions and a comparison of speech-act realisations in both the mother tongue and the foreign language should therefore become an issue in foreign language teacher education curricula and should be appropriately introduced into the classroom.

Furthermore, study of the use of compensatory strategies $(\mathrm{CpS})$ in foreign language communication will have to be made part and parcel of foreign language teacher education. The more incomplete our oral command of the foreign language, the more we shall have to revert to a skill of compensating for shortcomings in our competence. In order to be able to do that efficiently and effectively we need the necessary phrases and vocabulary, practice in using them appropriately and again, of course, awareness. The student teacher not only needs to become adroit in availing himself or herself of all sorts of $\mathrm{CpS}$, s/he also needs to be stimulated to think about the phenomenon itself and experience the use of $\mathrm{CpS}$ for communicative as well as learning purposes.

As foreign language learners we shall never become native speakers (NSs) of that language. This can never be the purpose of foreign language teaching. Therefore, in our communicating with speakers of the foreign language there will be a more complicated process of negotiation of meaning than is the case in our mother tongue. Beside a command of vocabulary and morpho-syntactic phenomena 
we need for this negotiating process a knowledge of language formulas (speech-act realisations and discourse regulatory formulas) and a skill in using them appropriately on the basis of our socio-cultural and metacommunicative awareness. The complexity of the process naturally entails misunderstandings. It is, therefore, not at all a wild thought to introduce exo-linguistic discourse into the input material that we confront learners with. This discourse contains misunderstandings that may typically arise between non-NSs (NNSs) and NSs, and between speakers of various European languages via a lingua franca. The inevitable use of all sorts of $\mathrm{CpS}$ (for vocabulary, but also for discourse regulation and speech-act realisation) in this sort of communication may serve as examples of an intercultural negotiating process and will reveal the importance of $\mathrm{CpS}$. It will also bring foreign language use nearer to the learner's experience and could therefore be more motivating.

Europe and its unification should not be made into a separate school subject. It needs to be integrated into topics dealt with in relevant school subjects. Foreign languages, on the basis of the above reasoning, as carriers of a cultural load, should be among those subjects.

Co-operation between all subjects concerned in school projects should be one of the ways in which Europe is given a place in the school curriculum. Obviously, in this context foreign language teachers need to be able to communicate with their colleagues in the other subjects. Therefore they should be given a basic introduction into Europe's history and its present state of affairs.

\section{FACING THE PROPOSALS OF THE LANGUAGE POLICY DIVISION (COUNCIL OF EUROPE)}

Whenever we pose a question on what most European foreign language teachers and foreign language educators have in common, the answers have to do with the fact that we come from countries that were recently committed to farreaching educational reforms, particularly of the objectives, content and methodology of modern language teaching. In the face of globalisation, on the one hand, and retreat into one's own identity, on the other, Europe has made the choice of building an open, multilingual and intercultural society in order that its rich cultural and linguistic heritage, its great diversity evidenced at a local, regional and national level, become a source of mutual understanding and enrichment. Schools naturally have an essential role to play and particularly the learning and teaching of modern languages that have been and remain a major concern of the Council of Europe and the European Union. Allowing all Europeans to acquire the competences necessary to communicate in several languages and to have the possibility of experiencing different cultures is now:

- a right and a necessity;

- the basis for intensified co-operation, whether it be bilateral, trilateral or multilateral, local and trans-border, professional or economic, cultural or university-related, individual or within the framework of an association;

- the guarantee for increased mobility and exchanges;

- the assurance of better access to information through media and ICT.
Living together in the 21 st century implies the desire to live. On the one hand, a globalised market; on the other, frustrated national identities. The face-off between market and identity generates two visions of the world: one which sees the Western model (market economy, parliamentary democracy and cultural tolerance) as gaining ground everywhere, and one which sees the world as a prey to savage cultural or religious conflict. What emerges from both is the separation of two worlds: the world of technologies and markets, and the world of cultures, instrumental reason, collective memory, signs and meanings. It is as if individuals and communities had a straight choice between hurling themselves into the flood of data and commodities produced by mass society, and shielding their identity by falling back on a revitalised sense of community.

The challenge is formidable for Europe as well as for TEFL teacher education in Europe, which has chosen to be open, multilingual and intercultural, and means to make the diversity of its local, regional and national linguistic and cultural heritage a source of enrichment and mutual understanding. The challenge is also formidable for schools:

- First of all, they are faced with young people whose learning process is becoming ever more chaotic (young people whose experiences succeed one another without ever coalescing to form a whole, who play several roles and live in several time frames).

- Secondly, schools are faced with accelerating loss of community, which is weakening reference points both spatial and temporal (spatial, because the new communications media are bringing the distant close; temporal, because the collective memory based on the things that people have shaped and lived through together is being lost, scattered and fragmented into individual or group memories). This loss of community also leads to a break with the reality principle, as people surrender to the wish to follow their own urges and instincts.

- Thirdly, schools are faced with 'virtualisation', as the information networks detach themselves from human experience, with multimedia manufacturing an alternative reality, and the illustrated press increasingly relying on computer-generated images, rather than straight photographs.

- Lastly, schools are faced with the new emphasis on selfimage, self-development and freedom of the individual, which disconnects people from group projects.

It is clear from this analysis, that languages have a strategic role to play. It is also clearer why the EU and the Council of Europe have paid so much attention to the themes of language and culture. This is why they have insisted that acquiring the ability to communicate in several languages and being able to experience several cultures constitute for every European today:

- a basis for improved co-operation (bilateral, trilateral and multilateral, territorial and cross-border, vocational and economic, cultural and academic, and also between associations and individuals);

- a guarantee of better access to information via the media and the information and communication technologies. 
This is also why the Council of Europe and the EU are committed to projects and activities:

- which allow individuals and groups to overcome the language and culture barrier, and decompartmentalise education, training and research;

- which promote and develop physical and virtual mobility;

- which help to give people a sense of belonging.

Probably nothing is further from interculturalism than breaking the world down into national, regional or other cultural units, which know nothing of one another, and have one obsessive ideal -a stifling homogeneity and purity. Culture and community must not be confused, because no modern society that is open to change and exchange enjoys complete cultural homogeneity, and because cultures are constructs which evolve by adapting to new experiences.

The Council of Europe and the EU have launched projects and actions which aim at moving beyond individual and collective linguistic and cultural barriers, creating synergies in the areas of education, training and research, encouraging genuine mobility, developing virtual mobility and contributing to the formation of a feeling of common European citizenship.

EU initiatives which deal with issues such as transnational mobility, life-long education, new approaches in language learning and teaching, access to new multimedia learning environments, the Net-days projects related to awareness-raising on the role of the information society in the area of learning, contribute to an enrichment of what one may call "European togetherness", or European citizenship ('citoyenneté Européenne').

This is also true of the language and intercultural initiatives of the Council of Europe's Language Policy Division: the CEFR (Common European Framework of Reference: Learning, Teaching and Assessment) and the ELP (European Language Portfolio) are planning instruments which support diversification in the area of language learning, contribute to promoting learner autonomy and encourage life-long learning. The research work of the Language Policy Division, widely known in the 1970s with the publication of The Threshold Level (and the subsequent versions of it for most European languages), was followed in the 1990s by the development of the CEFR (Council of Europe 2001).

The $\boldsymbol{C E F R}$, which became a full publication in 2001 (European Year of Languages) after two pilot editions (see http://www.coe.int/T/DG4/Linguistic/CADRE_EN.asp\#Top OfPage)...

- provides a common basis for the elaboration of language syllabuses, curriculum guidelines, examinations, textbooks, etc in a European dimension;

- describes in a comprehensive way what language learners have to learn to do in order to use a language for communication and what knowledge and skills they have to develop so as to be able to act effectively;

- defines a scale of 'common reference levels' of proficiency which allow learners' progress to be measured at each stage of learning and on a life-long basis;

- promotes an action-oriented approach to modern language learning in Europe

Equality for the speakers of different languages is essential if the EU is to become politically accountable. So active language policies can avert, as Phillipson (2002) has said, an American-English only Europe. Multilingualism and interculturalism are not easy to define. With a view to understanding them better a number of methodological objectives were set up in order to find out what this problem meant, in theory and in practice, in all the areas where it arose, in order to arrive at that "desire to live together, equal but different".

The $\boldsymbol{E L P}$ reflects the Council of Europe's concern with respect for diversity of cultures and ways of life and is a tool to promote multilingualism and interculturalism and integrates three elements (see http://www.coe.int/t/dg4/ portfolio/Default.asp?L=E\&M=/main_pages/welcome.html):

- The language passport (describing intercultural learning experiences). At the higher levels of proficiency, the selfassessment grid implies: explicit awareness of the sociopragmatic dimension of linguistic communication (e.g., B2 and C1 Reading, C1 and C2 Spoken interaction); some familiarity with the linguistically mediated culture of the target language (e.g., B2, C1 and C2 Reading, C2 Writing). At present no provision is made for selfassessment that focuses on non-linguistic intercultural practices.

- The language biography (including information on linguistic and cultural experiences gained in and outside formal educational contexts). At the higher levels, selfassessment checklists have the same intercultural implication as the self-assessment grid in the language passport. In certain cases they may focus in some detail on linguistically mediated culture. Most existing ELP models aimed at adult learners encourage the owner to write reflectively on intercultural experiences of various kinds, but usually without providing a specific focus.

- The dossier (giving value to the heritage language or languages of oneself). The selection of documents for inclusion in the dossier is the responsibility of the ELP owner and is an aspect of his/her self-assessment. The extent to which the selection explicitly seeks to illustrate the owner's intercultural competence is likely to be determined by the extent to which intercultural competence has been an explicit issue in his/her L2 learning experience.

The $\boldsymbol{E} \boldsymbol{L} \boldsymbol{P}^{l}$ can play an important role in this collaborative attempt to meet the challenge of multilingual and intercultural communication

- with its encouragement of all kinds of language learning;

\footnotetext{
${ }^{1}$ It is worth to note that there is an American version of the ELP, called Linguafolio, which is now being experimented by 5 States. The Virginia Department of Education began a pilot phase of the LinguaFolio Virginia for high school and university students in 2004-2005. Since then the program has expanded to include 5 states: Virginia, North Carolina, South Carolina, Kentucky, and Georgia. See: http://www.doe.virginia.gov/linguafolio/index.html
} 
- with its objective of providing additional motivation for language learning in schools and encouraging mobility of European citizens:

- with its role as a tool for social and professional integration;

- with its potential comparison of language learning in different European countries;

- with its importance as an interface and its need for diversification.

When intercultural competence is considered separately from communicative proficiency, two issues arise for the ELP. First, how it should provide for self-assessment of intercultural competence; and second, in what ways intercultural experiences can be captured in (i) the language passport and (ii) the language biography.

In their guide for ELP developers, Schneider and Lenz (2001: 36) point out that empirically validated descriptors for language learners' intercultural and socio-cultural competences do not yet exist. Such descriptors would not be directly related to levels of communicative proficiency: as Schneider and Lenz note, it is possible to have extended cultural knowledge on the basis of reading translations. They argue that it would be valuable to have lists of objectives detailing

- Aspects of socio-cultural knowledge (knowledge of history, politics, culture etc.).

- Components of intercultural competence that should be acquired (ability to handle differing norms and culturally induced misunderstanding, ability to prepare for and benefit from stays in regions with different cultures, etc.).

At this point, it is worth pointing out that cultural knowledge and intercultural competence are not the same thing. No doubt intercultural competence depends to some extent on relevant cultural knowledge, but it also depends on other factors, including the individual's affective and attitudinal orientation and interpersonal skills (see Council of Europe 2001: 104f.).

Even if we had empirically validated scales of intercultural competence, it is not certain that they would lend themselves to self-assessment, since they would necessarily differ from the common reference levels of the CEFR in one important respect. The Common Reference Levels are defined by descriptors that refer to communicative behaviour: on the whole we know what we are capable of doing and what lies beyond our competence. By contrast, the components of intercultural competence may well be opaque in the absence of reflected intercultural experience: in many circumstances ELP users may not be in a position to judge their own intercultural competence. G. Zarate (2000) has argued against the idea of self-assessment based on checklists and in favour of some flexible means of self-profiling. This is an attractive notion, but the devising of such a means implies significant further development of the $E L P$ in a wide EU educational context.
Much more recently, in October 2003, the Language Policy Division put forward its first pilot version of a Manual for relating Language Examinations to the CEFR. This Manual (see http://www.coe.int/T/DG4/Linguistic/ Manuel1_EN.asp\#TopOfPage) is the result of a working group, under the leadership of B. North, who has been able to put into practice the ideas and suggestions produced during the Helsinki Seminar in July 2002, in particular the need to assist member states, national and international providers of examinations, etc, in relating their certificates and diplomas to the CEFR. This preliminary version of the Manual, which has been piloted by a great number of relevant institutions and experts in member countries during the last few years, is expected to be published as a definitive version in 2008. The Manual helps users to:

- describe the examination coverage, administration and analysis procedures;

- relate results reported from the examination to the Common Reference Levels presented in Chapter 3 of the CEFR;

- provide supporting evidence that reports the procedures followed to do so.

Now that the CEFR and the ELP have been launched and are being developed as powerful educational tools through intensive and extensive international co-operation, the language teaching profession has demanded more and more coherence and transparency in language certification from formal and informal EU institutions. The DIALANG project and ALTE (Association of Language Testers in Europe) have already adopted the six level scale of the CEFR. But the mutual recognition of language qualification awarded by 'all' relevant UE institutions (in particular, in the context of formal academic bodies, in the sense that there is no doubt that a student's A2 in oral interaction obtained in a primary school in Madrid is the same as the one given to a student in Osnabrück) is still a claim for the coming years. In that sense, the Manual aims to:

- contribute to competence building in the area of linking assessments to the CEFR;

- encourage increased transparency on the part of examination providers;

- encourage the development of both formal and informal national and international networks of institutions and experts.

\section{CONCLUSION}

If the development of a "citoyenneté Européenne" in the student teacher and learner is taken seriously by teacher education institutions and schools we should realise that not only the social sciences, history and economics have a role to play in the planning and organisation of projects or courses aimed at furthering this development. Also foreign languages have a clear-cut and very important contribution to make. They will only be able, however, to make such a contribution if they develop from mainly form and grammar oriented to communication-oriented disciplines. This implies 
that on a par with issues concerning the forms of the foreign language, the realisation of speech-acts and routines for the regulation of discourse must also be taken seriously and learners must be encouraged and helped to use compensatory strategies to make the interaction as satisfactory as possible.

It also implies that next to consciousness-raising regarding the differences between mother-tongue and foreign language in the morphological and syntactic field, serious attention should be given to study of the differences between how other speech communities do things differently with words and have different ways of regulating discourse. Foreign language teaching does not only become more efficient and effective in this way but it may also make a contribution to the development of an intercultural awareness in the learner, which makes for better communication across borders, and which is a prerequisite for the europeanization of what are now still mainly nationalistic states. The development of the knowledge, skills and attitudes of the foreign language teacher that are necessary to help him or her play a stimulating role in the unification process of Europe, is a major task for language teacher education departments. They should work towards performing this task much more emphatically and explicitly than has been the case so far.

\section{ACKNOWLEDGEMENTS}

This research was supported in part by the Department of Education, Vocational Training and Educational Innovation of the Spanish Ministry of Education and Culture. There are no conflicts of interest.

\section{REFERENCES}

Beernaert, Y., Van Dijk, H., Sander, Th. (1993). The European Dimension in Teacher Education. Brussels: ATEE-RIF, SNW 4.

Bruce, M. (1990). Teacher Education and the Erasmus Programme. European Journal of Teacher Education 12, 3-4.

Buchberger, F., \& Beernaert, Y. (1996). Recent developments in teacher education in European Union. In Th. Sander, F. Buchberger, A. Greaves, D. Kallós (Eds.), Teacher Education in Europe: Evaluation and Perspectivas (pp. 393-405). Osnabrück: RuckZuck-Druck GmbH.

Byram, M., Gribkova, B., Starkey, H. (2002). Developing the Intercultural Dimension in Language Teaching: A practical introduction for teachers. Strasbourg: Council of Europe Language Policy Division.

Council of Europe (2001). The Common European Framework of Reference for Languages: Learning, Teaching, Assessment. Cambridge: Cambridge University Press. (Also available online from:
http://www.coe.int/T/DG4/Linguistic/CADRE_EN.asp\#TopOf Page).

Faerch, C., Haastrup, K., Phillipson, R. (1984). Learner Language and Language Learning. Clevedon: Multilingual Matters, 34, 45-63.

Grenfell, M. \& Harris, V. (2007). The strategy use of bilingual learners of a third language: a research agenda. Proceedings of the 5th International Conference on Third Language Acquisition and Multilingualism (pp. 1-14). Southampton: University of Southampton. (Also available online from: http://eprints.soton.ac.uk/48447/).

Hatch, E. M. (1983). Psycholinguistics: a second language perspective. Rowley, Mass: Newbury House.

Kelly, M., Grenfell, M., Allan, R., Criza, Ch., McEvoy, W. (2004). European Profile for Language Teacher Education -A Frame of Reference. Final Report. Brussels: Directorate General for Education and Culture.

Nattinger, J. R. \& DeCarrico, J. S. (1986). Lexical Phrases, Speech-Acts and Teaching Conversation. AILA Review 6, 118-138.

Phillipson, R. (2002). English-only Europe? Language Policy Challenges. London: Routledge, 1698-1981.

Phillipson, R. \& Skutnabb-Kangas, T. (1999). Englishisation: one dimension of globalisation. AILA Review 13, 19-36.

Richards, J. C. \& Nunan, D. (Eds.) (1990). Second language teacher education. Cambridge: C.U.P.

Sander, Th. (1993). Discussing the meaning of the European dimension in teacher education: criteria, problems, implications. In Y. Beernaert, H. Van Dijck, Th. Sander (Eds.), The European Dimension in Teacher Education (pp. 35-57). Brussels: ATEE Publications.

Schneider, G. \& Lenz, P. (2001). European Language Portfolio: Guide for developers. Strasbourg: Council of Europe.

TNTEE Publications (1999). Teacher Education in Europe in the late 1990s. Evaluation and Quality. TNTEE Publications, v. 2, 2. Umea: TNTEE.

Vez, J. M. (1995a). Le véhicule de culture de proximité. In J.-P. Atal et al. (Eds.), Comprendre les langues, aujourd'hui (pp. 95-108). Paris: La TILV.

Vez, J. M. (1995b). Perspectives communicatives et développement des curricula des langues européennes. E.L.A. (Etudes de Linguistique Appliquée) 100, 55-66.

Vez, J. M. (1995c). The social context of EFL. In D. Madrid \& N. McLaren (Eds.), A Handbook for TEFL (pp. 15-37). Alicante: Marfil.

Vez, J. M. (2000). Fundamentos lingüísticos en la enseñanza de lenguas extranjeras. Barcelona: Ariel, 1-15.

Vez, J. M. (2001). Formación en didáctica de las lenguas extranjeras. Rosario (Argentina): Homo Sapiens, 5-30.

Vez, J. M. (Ed.). (2002). Didáctica de la lengua extranjera en educación infantil y primaria. Madrid: Síntesis.

Vez, J. M. \& E. Martínez (2002). Competencia Comunicativa Oral en Lenguas Extranjeras. Investigación sobre logros del alumnado gallego de Inglés y Francés al finalizar la ESO. Santiago de Compostela: ICE, Servicio de Publicaciones de la USC, 20 (48): 244-303.

Zarate, G. (Ed.). (2000): Cultural Mediation and the Teaching and Learning of Languages. (Workshop Report 4/2000). Graz: European Centre for Modern Languages. (Also available online from: http://www.ecml.at). 